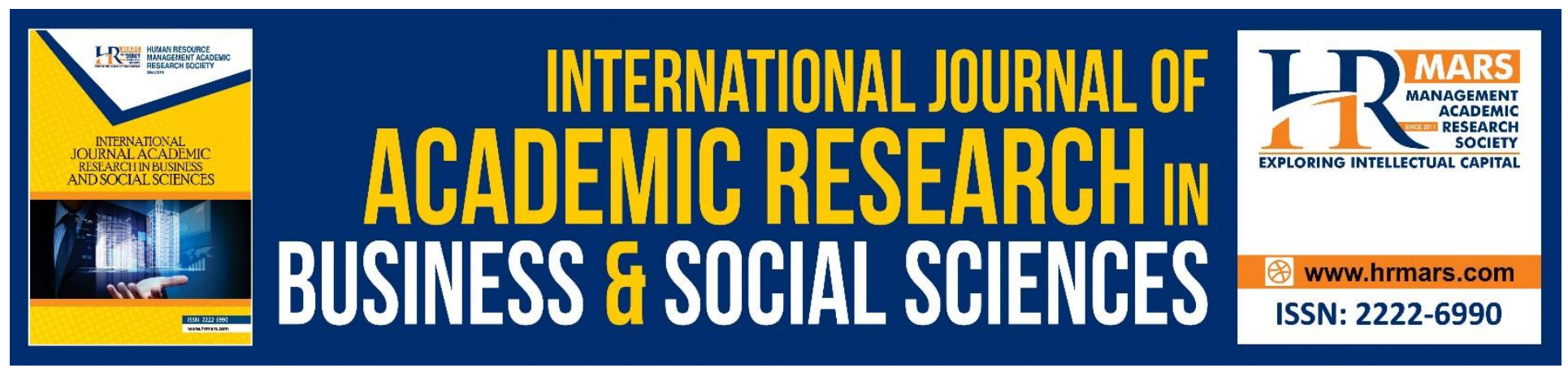

\title{
Coping with Teaching and Learning Creative Arts in Malaysian Public Universities in The Time of Covid-19 Pandemic
}

Connie Lim Keh Nie, Yow Chong Lee, Chow Ow Wei

To Link this Article: http://dx.doi.org/10.6007/IJARBSS/v11-i14/8942

DOI:10.6007/IJARBSS/v11-i14/8942

Received: 09 December 2020, Revised: 13 January 2021, Accepted: 12 February 2021

Published Online: 30 March 2021

In-Text Citation: (Lim et al., 2021)

To Cite this Article: Lim, C. K. N., Yow, C. L., \& Chow, O. W. (2021). Coping with Teaching and Learning Creative Arts in Malaysian Public Universities in The Time of Covid-19 Pandemic. International Journal of Academic Research in Business and Social Sciences, 11(14), 337-358.

\section{Copyright: (C) 2021 The Author(s)}

Published by Human Resource Management Academic Research Society (www.hrmars.com)

This article is published under the Creative Commons Attribution (CC BY 4.0) license. Anyone may reproduce, distribute, translate and create derivative works of this article (for both commercial and non-commercial purposes), subject to full attribution to the original publication and authors. The full terms of this license may be seen

at: http://creativecommons.org/licences/by/4.0/legalcode

Special Issue: Contemporary Business and Humanities Landscape Towards Sustainability, 2021, Pg. 337 - 358 http://hrmars.com/index.php/pages/detail/IJARBSS JOURNAL HOMEPAGE

Full Terms \& Conditions of access and use can be found at http://hrmars.com/index.php/pages/detail/publication-ethics 


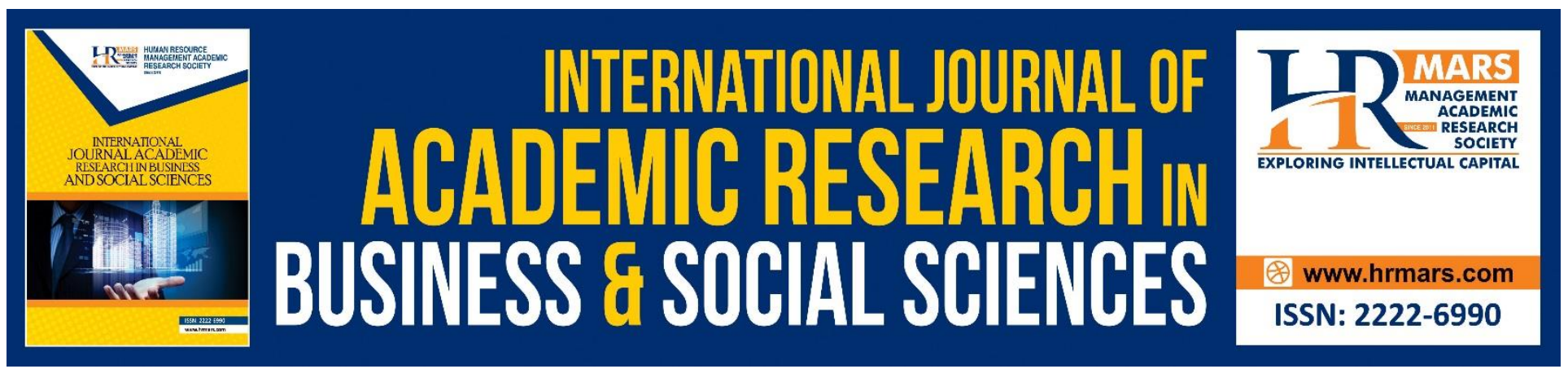

\title{
Coping with Teaching and Learning Creative Arts in Malaysian Public Universities in The Time of Covid-19 Pandemic
}

\author{
Connie Lim Keh Nie, Yow Chong Lee \\ Faculty of Applied and Creative Arts, Universiti Malaysia Sarawak, Kota Samarahan, Sarawak \\ Email: Iknconnie@unimas.my/climkn@gmail.com

\section{Chow Ow Wei} \\ Faculty of Human Ecology, Universiti Putra Malaysia, 43400 Serdang, Selangor, Malaysia.
}

\begin{abstract}
The unprecedented COVID-19 pandemic has disrupted the operation of Malaysian public universities and infinitely affected the way academics work. It is a devastating challenge where academics in the field of creative arts strived to cope with a transition from shifting face to face studio-based teaching and learning activities to online teaching and mentoring. This gave rise to a sudden change for them to carry out their administrative duties full-time at home and to re-adjust to alternative academic activities during the cordon sanitaire. This article describes the experiences and unusual situations faced by the academics, as well as their responses to this crisis in different dimensions starting from the initial stage of the Movement Control Order until the period they resumed work in the university office. The discussion proceeds with how the global pandemic has affected their teaching routine in the field of creative arts at present with a focus on music and film specialisations. This phenomenonderived ethnography significantly employs self-conscious observation along the online teaching process uniquely conducted for a few respective courses in designated Malaysian public universities when the pandemic-triggered disruption was experienced. With a discussion only limited to observation based on the data gathered for the teaching component, the authors hope to recommend a practical approach in reinvigorating academic practices during and post COVID-19 period.
\end{abstract}

Keywords: COVID-19, Pandemic, Academics, Creative Arts, Teaching and Learning

\section{Introduction}

The Novel Coronavirus-19 or COVID-19 poses a global pandemic that is presently sweeping across all aspects of life. As of February 5, 2020, this lethal contagion had infected a global population of about 105.5 million and claimed over 2.3 million lives worldwide, including 238,721 confirmed positive 
cases and 857 deaths in Malaysia (Johns Hopkins University \& Medicine, n.d.). Consequently, it has dramatically affected the workforce across the world in work-life balance including academics. To combat the containment of the coronavirus, on March 16 Malaysia's newly appointed Prime Minister Muhyiddin Yassin announced the enforcement of 2020 Malaysia Movement Control Order (MCO hereafter), a cordon sanitaire executed in phases starting March 18 (Sukumaran, 2020). This pandemic has caused social and economic impacts globally as social practices and customs have changed drastically for the serious consideration of safety measures, and citizens would need to learn and adapt to a new way of living generally known as a 'new normal'. They are to learn immediately new ways to communicate, how society functions and how businesses continue to operate. The mind set of 'business as usual' will have to be discontinued.

In the tertiary education scene, nationwide universities in Malaysia were forced to close but academics were later instructed to mandate all teaching and learning activities remotely using online facilities until the end of the year (Saif et al., 2020). During the COVID-19 lockdown, in the creative arts faculties the digital transformation of teaching content accelerated, bringing in trendy customs as well as new challenges to the teaching and learning process. Like other workers of other sectors, academics in universities were to necessarily comprehend the global pandemic and to act resilient toward the possible changes in the norm they used to know. They were also expected to adopt to and master the blended synchronous and asynchronous applications in teaching and learning. A more pertinent issue underlying in this discussion is also addressed through the understanding of compatibility, competitiveness and sustainability whether an academician can stay long in the profession post-COVID-19.

At the first phase of MCO, universities in Malaysia had announced the postponement of the semester. Some intended to resume the online teaching and learning activities as early as April 1 (UNIMAS News, 2020). However, the announcement was then retracted as postponement till April 27 as confirmed by the Ministry of Higher Education (Kalbana Perimbanayagam, 2020; Ministry of Higher Education, 2020). Uncertainties loomed amidst the unknown situation of when and how the classes should be conducted online since many lecturers had never experienced delivering online lectures, let al.one online studio-based classes. In compliance to the lockdown, students who stayed in hostels were not allowed to leave campus and had to give in to daily supplies of food and groceries from their residential colleges. Academics, especially those with administrative posts, were expected to bridge the university management with students by channelling both information and sometimes emotional support, which was conducted through counselling services in common practice (Abu Karim, 2020).

Corbera et al. (2020) has brought to light the issues within the academic profession by calling for the transformation of "work ethos now and in the future":

"This disruptive time can become an opportunity to foster a culture of care, help us refocus on what is most important, redefine excellence in teaching and research, and in doing so make academic practice more respectful and sustainable" (Corbera et al., 2020, p.191) 
In response to the quote above, and in line with our present environment, a number of questions arise: What does COVID-19 mean to the academics? How do they shift their face-to-face teaching to blended learning and e-leaning modes effectively? What are the challenges they face in teaching and learning activities? What are the adaptations and changes necessary throughout the MCO period? Confronted with the many facets as well as considering the consequences of COVID-19 pandemic in Malaysian universities, academics perceived that this unprecedented situation had made a huge impact on the delivery of knowledge, with a forced motivation to shift and transform the conventional face-to-face teaching to online teaching mode overnight. Approaching from the perspective of lecturers, this paper explores the challenges faced by lecturers at Malaysian public universities and recalls the ways teaching and learning activities were carried out in the field of creative arts, particularly in music and film studies during $\mathrm{MCO}$ and $\mathrm{RMCO}^{1}$ periods in Malaysian universities. The discussion is only limited to an observation based on the data gathered for the teaching component.

\section{Literature Review}

Salmi (2000) envisages that the emphasis of globalisation as a significant economic trend, the growing role of knowledge, and the information and communication revolution in the 21st century would increasingly pose drastic challenges to single out 'traditional' higher learning systems and institutions in the 21 st century (2000, pp.3-5). Twenty years later, after the development of the rising importance of 'methodological knowledge and skills' while the learning of facts and basic data per se loses its weight in the teaching and learning process (Salmi, 2000, p.7), higher education has apparently met with another challenging factor such as lack of physical interaction due to remote learning. After the World Health Organization declared COVID-19 as a global pandemic in March 2020, this situation challenged the education system globally and forced the shift of conventional face-to-face teaching mode to online teaching mode overnight. With interchangeable terminology such as e-learning, blended learning, computer-mediated learning, web-based learning and open learning, the technology that defines the online learning mode determines the possibility of teaching and learning activities that could be performed in any rhythm, anywhere, anytime with any means as long as there is an internet connectivity (Cojocariu et al., 2014). A report by United Nations Educational, Scientific, and Cultural Organisation (n.d.) on April 4, 2020 indicated that over 1.5 billion learners were disrupted globally and they were not able to return to their universities or schools during the worldwide enforced restriction period. For instance, since the quarantine measures started in China, which has the world's largest population, almost 276 million students of schools and universities had been affected (Huang et al., 2020b). Expeditiously, "ensuring learning undisrupted when classes are disrupted" became a slogan initiated by China's Ministry of Education as a reform of the education system through an online learning component (Huang et al., 2020a). Ensuring undisrupted learning, online learning has become the only operational tool to make the teaching and learning process possible during the COVID-19 pandemic outbreak periods.

In the pre-COVID-19 time, academics and students have been exposed to a new learning method known as 'blended learning' through an e-learning portal. Five years ago, the concept of blended learning in the asynchronous mode was introduced where both physical and virtual classrooms are

\footnotetext{
${ }^{1}$ RMCO stands for 'Recovery Movement Control Order', a less restricted phase to observed from June 10 and August 31.
} 
meant to be separated ( $\mathrm{Li}$ et al., 2020). Online learning has been already customised by some universities through e-learning portals ${ }^{2}$ in the asynchronous mode and lecturers were trained to share the learning resources with learners through designated e-learning system. At present, in compliance with the guidelines to control the spread of COVID-19 (Centre for Disease Control and Prevention, 2020; World Health Organisation, 2020), Malaysian universities mandated online learning as an alternative method to face-to face teaching starting from April 27 until December 31, 2020 (Landau, 2020; Pfordten, 2020, Sani, 2020; Teoh, 2020). However, many critical challenges have arisen when academics were required to hastily turn the blended asynchronous learning mode to blended synchronous learning (Dotterweich \& Rochelle, 2012) in order to conduct real-time lectures on the online platform. This overnight shift has indeed imposed a certain pressure for academics to transform the entire pedagogical approach from the conventional teaching method into a virtual classroom teaching approach.

This sudden change has no doubt turned into an uneasy situation for staff members in the faculty management, curriculum development and management division, quality assurance and academic development divisions in higher learning institutions, when all teaching staff was required to rethink and restructure their knowledge delivery methods from face-to-face delivery strategies to alternative methods (LeBlanc, 2020; Khalili, 2020; Erikson, 2020). Seeing online learning as a teaching tool it is defined as,

"learning experiences in synchronous or asynchronous environments using different devices (e.g., mobile phones, laptops, etc.) with internet access. In these environments, students can be anywhere (independent) to learn and interact with instructors and other students" (Singh \& Thurman, 2019).

In a synchronous learning environment, the real-time interaction between a lecturer and students during live lecture sessions enables the lecturer to give instant responses, comments and feedback to the questions and opinions raised by the students. It provides a social interactive space where the students have opportunities to expressed their opinions and exchange the opinions and ideas among each other (McBrien et al., 2009). On the other hand, asynchronous methods are not real-time based. Learning materials such as videos and pre-loaded lecture notes are made available on the course elearning portal and students can enjoy the advantage of access whenever there is an internet coverage and the flexibility to learn at their own pace at their convenience and space (Ahmad Fuad Abdul Rahim, 2020). Although the advancement of technology had created a virtual space where the students were able to interact with their lecturers and peers during isolation, there was an absence in the sense of 'human touch' in a learning community (Khailili, 2020). Asynchronous and synchronous online teaching, however, is nothing new in academia as an additional resource for students (Phirangee \& Malec, 2017). Both Erikson (2020); Khailili (2020) presented such condition as a conundrum, in which the lecturers are required to explore the various available online tools in order to conduct teaching and learning activities; on the other hand, there are some lecturers who are

\footnotetext{
${ }^{2}$ Many universities have developed their learning management system popularly known as Moodle, which is a modular object-oriented dynamic learning environment. The learning portal is customised as eLEAP in Universiti Malaysia Sarawak, and as PutraBLAST in Universiti Putra Malaysia.
} 
trying to catch up and adapt themselves into 'new normal' online teaching practice while struggling and experiencing a high level of stress.

As a 'panacea for crisis', implementation of online learning or blended learning is no longer an option for academics but a necessity in the pandemic time for teaching and learning activities (Dhawan, 2020). Accomplishing online learning during this remarkable time period, the main concern is not to argue and question about the quality of education, but, it is a time period challenging both the academics and students immensely to adapt and adopt the three distinct attributes "distance, scale and personalization" in virtual classrooms (Carey, 2020). Ahmad Fuad Abdul Rahim (2020) expressed a good internet speed and time management are key requirements of online teaching. An Indonesian lecturer recalled that among the challenges he faced with his students during the pandemic were students' affordability to the internet access subscription, the selection on low bandwidth for online learning applications, and a clear explanation on the assignments given to the students (Allo, 2020).

\section{Methodology}

This study predominantly covers how the authors playing the roles as researchers coped with challenges by having innovative instructional strategies implemented in teaching and learning activities during the MCO period to ensure the continuity of online learning. The COVID-19 pandemic phenomenon can be seen as a philosophical experience, as it combines aesthetic theories as "truthful and useful abstraction through human experience of the phenomenological relationship to the world" (Nechvatal, 2011, p. 231). As a tool of phenomenological study, a research approach was used where a methodology of autoethnography was chosen to enable the authors to selectively coin significant subjects of their lived experiences during the MCO period in the teaching and learning process.

While working from home during the MCO period the authors who currently work in Malaysian public universities in the field of creative arts, found themselves at different locations within the national border. This obligatory condition has overwhelmingly enabled each author, who obviously played the role as a researcher, to similarly act as a participant to a forced, infinite setting as lived experience where the cognition of the pandemic, the world, the employment and even the self-existence is unconditionally challenged. It was also a monumental instant for a researcher/ participant to open up to an individual lived experience in this phenomenon with full consciousness. A physical detachment leads to isolation and disorientation, but a remote connectivity to the separated reality is on high demand through technology-mediated communication platforms. The quarantine situation therefore prompted the authors to a research set-up that was appropriated to the interest of the academics. A global phenomenon illuminated different responses towards the inspection of various questions on the creative arts education of higher learning in post-COVID-19 Malaysia. In this study, the lived experiences of being an academic during the MCO period was drawn upon. The autoethnographic accounts, anchored from observations, ideas and thoughts were made extensively feasible via the accessibility of the cloud-based internet facilities before they were gathered and then developed into several themes for this study.

The authors departed from the analytic branch of autoethnography which allows the researchers' "engagement in the situation to be included in the analysis, adding to the theoretical understanding 
of the social process" (Bunde-Birouste et al., 2019, pp. 509). The narrative of the researchers will not speak for itself but it requires interpretation when it is used as data (Reissman, 2005). This study introduces an autoethnography case study employed throughout the initial cordon sanitaire period as they were still required to be actively involved in an alternative teaching and learning process (Figure 1). Findings of this research capture the essence of events happening within the 3-month work-from-home period, specifically from March 18 till June 14, 2020, where the challenges and process of transitioning from face-to-face teaching to online teaching and learning are illuminated.

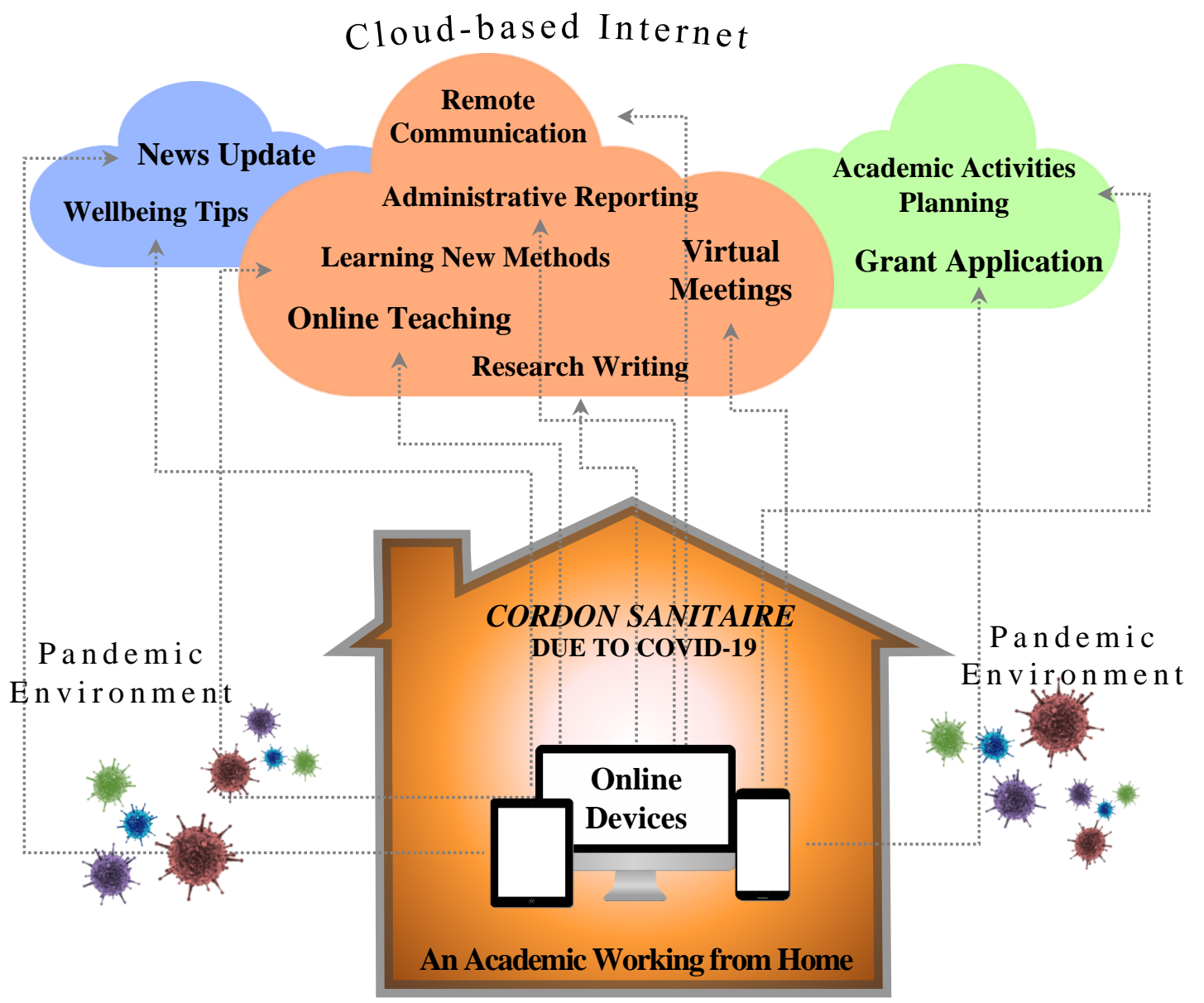

Figure 1: A conceptual framework showing how this autoethnographic study works when researchers could solely rely on the cloud-based internet via online devices when Movement Control Order in Malaysia was enforced in March 2020.

The ethnographic data of this study are collected based on the observation and the assessment output from the teaching experience of a few courses, namely "Music Theory II", "Introduction to Basic Music", "Film Theory and Criticism" and "Writing Skills in Music", offered currently in the respective universities. These courses were initially scheduled to be conducted face-to-face in the semester of February 2020, but after teaching was disrupted due to the MCO, they were later resumed as mandated online lectures which appeared as a rare scenario for the teaching and learning process experienced by both lecturers and students. Hence, 'following the flow' turned out as a 
significant criterion for the phenomenon-derived ethnography, as the authors' lived experience in regulating these courses to fulfilment amid the dynamic changes, which were brought up by the rare pandemic situation, emerged as a unique setting of the ethnography. Neither the allocated courses nor the hybrid teaching mode ${ }^{3}$ serves as a pre-requisite condition for this study. Through a narrative interpretation based on observations and personal reflection, they attempted to evaluate what the COVID-19 pandemic means to them as academics, and how this phenomenon transforms the teaching and learning routine in the field of creative arts while the world is expected to embrace a praxis of the 'new normal'.

\section{Results and Findings}

\section{Academics Challenges Pre- and During COVID-19 Pandemic}

While working from home during the MCO period, the researchers were made to re-evaluate, reflect and rethink the ethics in their professions as academics. Academia is an intensely competitive and rapidly changing environment. In a Malaysian university, faculties and institutions were all pursuing to fulfil the criteria for university ranking within the country and globally. Referring to the university ranking methodology, among the assessment criteria are teaching, research, citations, international outlook and industry income (THE World University Rankings, 2020). Academic reputation, research citation index, industry collaboration locally and internationally are key performance indicators for ranking assessment (O'Callaghan, 2020). Persuaded by 'academic praxis' in the form of 'performance and productivity', each individual academic will be measured by their personal contribution to the university in the area of teaching, research, publication, administrative duties, community services and work ethics. Pursuing excellence in the field of academia involves a costly endeavour (Ling, 2020; Lashuel, 2020). While in the confinement period, it was a time for the academic to reflect and redefine what is academic excellence.

Suddenly, since the MCO period started, academics became digital workers, transforming their conventional teaching in a lecture hall to a/the virtual classroom. In order to prepare academics to deliver online teaching, universities conducted workshops in the form of webinars to equip lecturers with digital tools in online teaching and various modes of alternative assessment research matters during the MCO period. This is also the time when many e-learning practitioners and advocates were invited to share their knowledge, insights and experiences to educators in their higher learning institutions through webinars. ${ }^{4}$ While working from home, the academics were overwhelmed with information and resources related to teaching and learning approaches as well as assessment methods. This confinement period was also a period where academics were urged to catch up and

\footnotetext{
${ }^{3}$ In the actual situation, the hybrid teaching mode adopted within the disrupted semester in the universities as observed was initially the conventional face-to-face lectures in the first half of the semester and succeeded by online lectures that were in the nature of blended synchronously and asynchronously learning style.

${ }^{4}$ These webinars are commonly coordinated by teaching and learning centres of selected institutions such as University of Malaya (Academic Enhancement and Leadership Development Centre, n.d.), Universiti Sains Malaysia (Centre for Development of Academic Excellence, 2021), Universiti Putra Malaysia (Centre for Academic Development, 2021) and Universiti Malaysia Sarawak (Centre for Applied Learning and Multimedia, n.d.). Some rather renowned e-learning advocates, such as Abd Karim Alias, the Director of the Centre for Development of Academic Excellence (CDAE), Universiti Sains Malaysia and Chuah Kee Man, the Deputy Director (Teaching Excellence) of CALM, UNIMAS, have initiated their sharing sessions through online platforms such as YouTube and Facebook (Abd Karim Alias, n.d.; Chuah, 2020).
} 
patch up with current online teaching practices at the same time to find out what are the suitable digital tools and approaches to be used in the discipline of creative arts in teaching and learning activities.

Undoubtedly, the MCO was a time to stay and work from home, and there was only a thin line between personal time and working hours. The ironic duality of 'unlimited freedom and invisible restraint' was the best summary to describe this boundless experience: everyday one could basically do whatever one wants according to the set goals of the year, but the job nature as an academic is always open-ended, causing one to respond to virtual demands at a '24/7' basis. ${ }^{5}$ Weekdays and weekends were equalised, and public holidays had lost their practical meaning. At leisure, the same digital applications such as email and chatting apps overlapped and intertwined with those at work.

Amidst the many uncertainties of the MCO implementation and much deficiency in the knowledge on COVID-19, lecturers had to play the roles of both a receptive news collector and an active messenger despite their physical immobility caused by the lockdown implementation. The researchers viewed this situation as a forced epistemological process of learning COVID-19 pathology, the pandemic dynamic statistics and the problematisation due to the atypical phenomenon. The internet media and messenger platforms were the only gateway that connected us with the 'world' outside our window panes-both the quiet physical realm and the busy, taxing mediated virtual dimension where happenings in reality are veined. One may need to redefine workspace and daily schedule. A global pandemic may be a wake-up call for academicians to be mindful in having a work life balance, maintaining good mental health and a healthy wellbeing.

\section{Coping with Online Teaching during COVID-19 Pandemic}

The COVID-19 pandemic as a phenomenon has toppled any known rules in teaching and learning in a public university. The enforced MCO has suddenly turned the conventional classroom artefacts from reality such as teacher, learner, teaching material, learning activity and assessment paper into mythos. Consultation meeting hours were suspended and planned summative assessments were cancelled, while ensemble classes were in limbo. For conventional lecturers, the gap to cope with new requirements in teaching and learning surfaced. Their core function will be void if they do not accomplish overnight to be significantly well-versed in digital device skills and alternative assessment methods in trend.

In Malaysian universities, starting from March 28, 2020 the e-learning unit started a series of training programme webinars which were free of charge (Centre for Academic Development, 2021) with the aim to equip lecturers to be tech-savvy in using various available digital tools in teaching and learning activities. In order to cope with these seemingly unconquerable challenges, it took a simple determination and self-motivation for academics to transcend the experienced limitations, thus learning to embrace the challenges. In addition, the researchers acquired advanced information on various types of online platform and media applications, to understand the boons and banes of each tool, and the limitations and preferences of the researchers' students (Figure 2).

\footnotetext{
${ }^{5}$ The Cambridge Dictionary defines this commerce term as "done, lasting, etc. for twenty-four hours a day, seven days a week" (Cambridge University Press, 2020).
} 
The line-up of media influencers that appeared on researchers' phone screens were also the source of knowledge and inspiration in teaching as they looked at the contents and contexts to find a contemporary connection with their subjects. For instance, using a YouTube video playlist of coronavirus songs as a reference source for students to write a music review as an assignment. ${ }^{6}$ This was the time when the roles and values of teachers and learners transformed dynamically and dramatically into an isolated and less sociable manner. While mastering media technology and enabling learning to happen at all places and at all times there was unavoidable criteria to deliver a satisfactory job as a university lecturer. This lesson was especially essential for lecturers in performance courses who faced the biggest challenge in maintaining the essence of the course outcomes as well as assessing performance skills without meeting the students face to face.

During the confinement period, academics were asked to transform the format of their lectures from physical in a lecture hall with face-to-face contact with students to online teaching. It was a period of time where academics were going through the process of restructuring, redesigning and rethinking of how music and film courses could be taught through online teaching. Both academics and students had their challenges in transitioning to an online form of teaching and learning. Taking into consideration the geographical locations of the students, some of the them came from rural areas that may not have access to computer and high-speed broadband internet facilities. As academic staff, among the concerns burning in our minds was whether our students were well equipped with technological tools such as personal computers or laptops with sufficient internet connectivity. Do our students have internet connectivity with sufficient mobile data, internet speed or Wi-Fi facility at their respective hometowns with sufficient download and upload speed to support their online learning activities, which includes attending online lectures, participating in online learning activities and access to scientific knowledge online? As the majority of the students were relocated in their respective hometowns, they needed to readapt and redefine their work-spaces to accommodate online learning.

One of the controversial issues faced by the students was technical difficulty in accessing online classes and assessments. Among the less fortunate, a student from Universiti Malaysia Sabah stayed "overnight in a tree to get better internet connection for online university exams" while her "selfdocumentary' went viral on social media and the news media (Lee, 2020) and she later received a scholarship from her respective university to pursue her bachelor's degree (Miwil, 2020). Such news has great impact, although temporary in nature, on economic inequality and facility accessibility to people who live far away from the cities. This also prompted higher learning institutions and academics to ponder how effective their online classes could be.

An inequality of education has been seen in this COVID-19 pandemic. Students who have internet access and connectivity anytime, anywhere have more opportunities to engage with the course materials, attend real-time lectures, participate in activities created by the lecturers such as forums,

\footnotetext{
6 This resource was customised as the online assessment material for courses of "Introduction to Basic Music" and "Writing Skills in Music". Both courses have different target learners: the former is for non-music students, while the latter is adapted for undergraduates of Bachelor of Music.
} 
quizzes and online assignments in an e-learning portal. In order to rectify the first challenge faced by the students who lived in the rural areas, assessing the accessibility to internet connection was needed. Despite the fact that most of the students own a smart phone with $4 \mathrm{G}$ compatibility which enabled them to connect to internet and enabled them attend real-time online lecture, it required each individual student to ensure they have sufficient mobile internet data to accommodate the online learning activities. If the students did not have internet service at home, they either subscribe to a mobile internet data package with monthly subscription fees to be paid or reload their mobile internet data from time to time. This could cause financial burden to the students who solely depend on their mobile internet data or wife services. Acknowledging the challenges faced by the students, online resources such as videos posted on an e-learning portal were reconfigured for the students to watch on low bandwidth. While choosing online platforms to conduct real-time lecture sessions, the lecturers also considered the amount of data consumed and file sharing limit per hour (Figure 2) as this would provide a financial implication for students to plan how much they needed to spend on their mobile internet data.

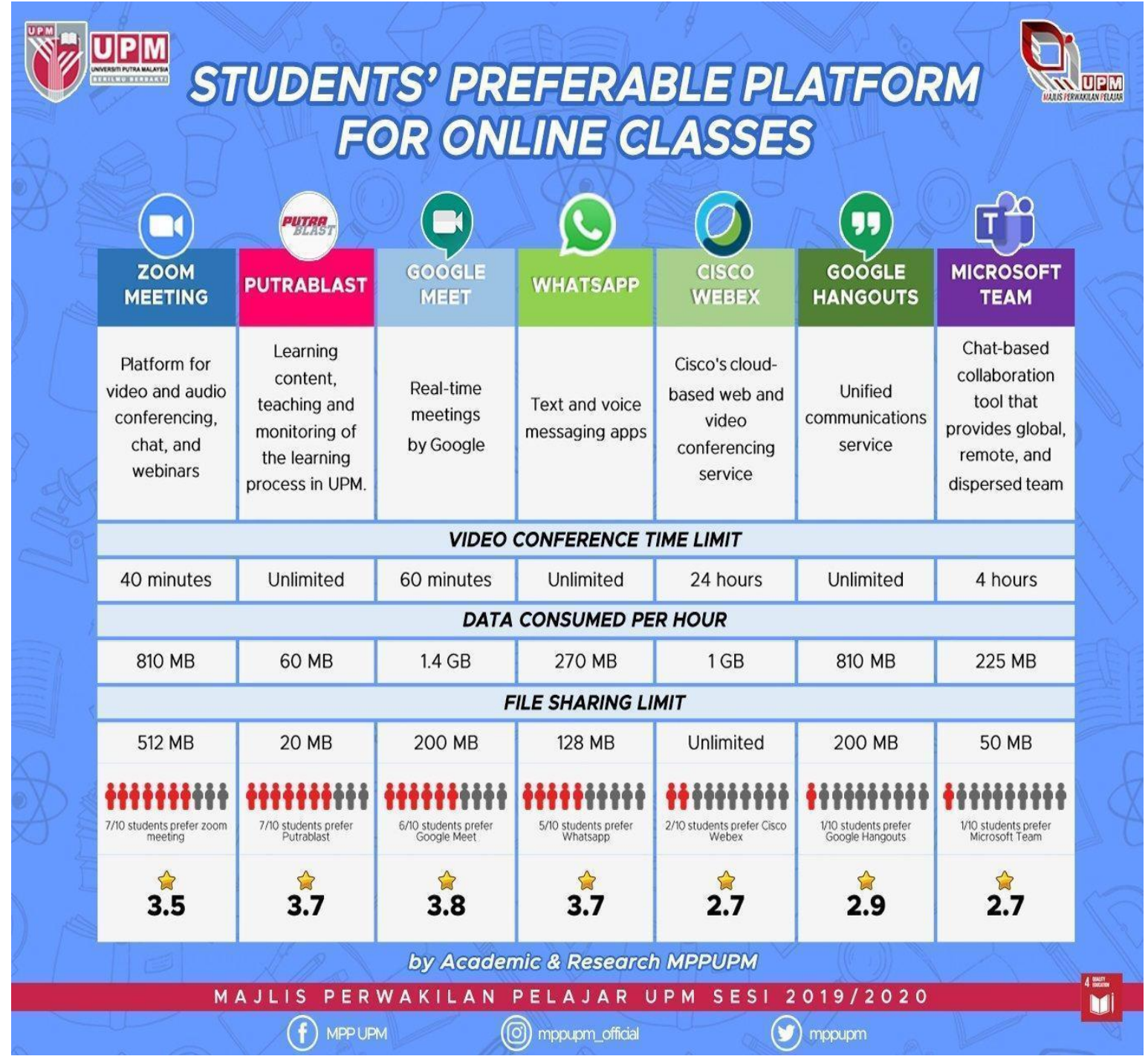

Figure 2: A comprehensive survey on UPM students' preferable platform for online classes 
Concurrently, COVID-19 had revealed inequities in learning (Williamson et al., 2020). Not every student has a stable internet and a decent space at home with a learning environment. Due to logistical reasons, there are students who live in rural areas that are required to travel to the nearest town or to a suitable space with internet connection to attend online lectures and to catch up with assignments and participate in activities posted by the lecturers on the e-learning portal. It could also be a financial burden for students who strongly depend on mobile data subscriptions to access the internet. Responding to the question raised by Lederman (2020), whether or not online learning will benefit the students, it very much depends on a students' learning attitude. The student's attitude and passion in learning the subject is crucial. This main factor serves as a driving force for a learner to pursue further to be motivated in self-directed learning in the particular subject. Hence, adapting to online classes and assessments inevitably requires a certain amount of flexibility from both the academics and their students. The academics have to be flexible enough to learn new skills while adopting unconventional teaching and assessment methods, on one hand. And on the other hand, they need to allow students to adapt to such changes with flexible feedback and submission times.

While the lecturers were working from home, both lecturers and students are living in isolation. With seven to eleven weeks of online teaching, the first ever teaching and learning activities conducted without physical learning contact, lecturers were to ensure no students were left behind throughout the processes. Therefore, in order to cater to personal learning pace and the learning needs of each individual student, the lecturers were handling remote supervision, online tutorial sessions, and responding to students' enquiries related to academic matters through email, WhatsApp and Telegram messages while working from home. In order to monitor the dynamics of the students' learning activities, the lecturers also created WhatsApp Group/ Telegram Group chats to ensure that the announcements and notices reached the students from time to time.

From the time the online teaching started, one of the researchers started to conduct real-time lectures in synchronous mode. It was a trial to see how effective the class could be conducted. The researchers found that not all students would be able to access the internet due to their location and broadband strength in their hometowns. Taking into consideration the limitations of synchronous online classes of both "equity and access" (Flaherty, 2020), the researcher had later opted to balance up both synchronous and asynchronous online lecture modes and sought a balance where both modes of lecture could complement each other in a time when a face-to-face lecture setting was impossible. In order to reduce the students' time and mobile data cost for synchronous classes, the researcher had pre-recorded his lectures on "Film Theory and Criticism" and shared them with his students a day before the synchronous class. Together with a worksheet, the students were asked to watch the lecture videos uploaded on YouTube while answering the attached worksheets as a guide to comprehend what they were learning. When it came to the real class time using video conferencing platforms such as Microsoft Teams, Cisco WebEx, Google Meet and Zoom, the researcher optimised this interactive opportunity to gain insight of the students' learning needs by having them inform on which subtopics required the lecturer's special attention and to be readdressed immediately (Figure 3). The classes often ended with students' reflections on what they had learned and an asynchronous quiz to be completed by students at their own convenience within 
INTERNATIONAL JOURNAL OF ACADEMIC RESEARCH IN BUSINESS AND SOCIAL SCIENCES

Vol. 11, No. 14, Special Issue: Contemporary Business and Humanities Landscape Towards Sustainability, 2021, E-ISSN: 2222-6990 @ 2021 HRMARS

the deadline given. It was the researcher's aspiration to provide a seamless learning experience transitioning between synchronous and asynchronous methods.

2

Which of the following sub-unit appears to be the most difficult to you and need me to address it today?
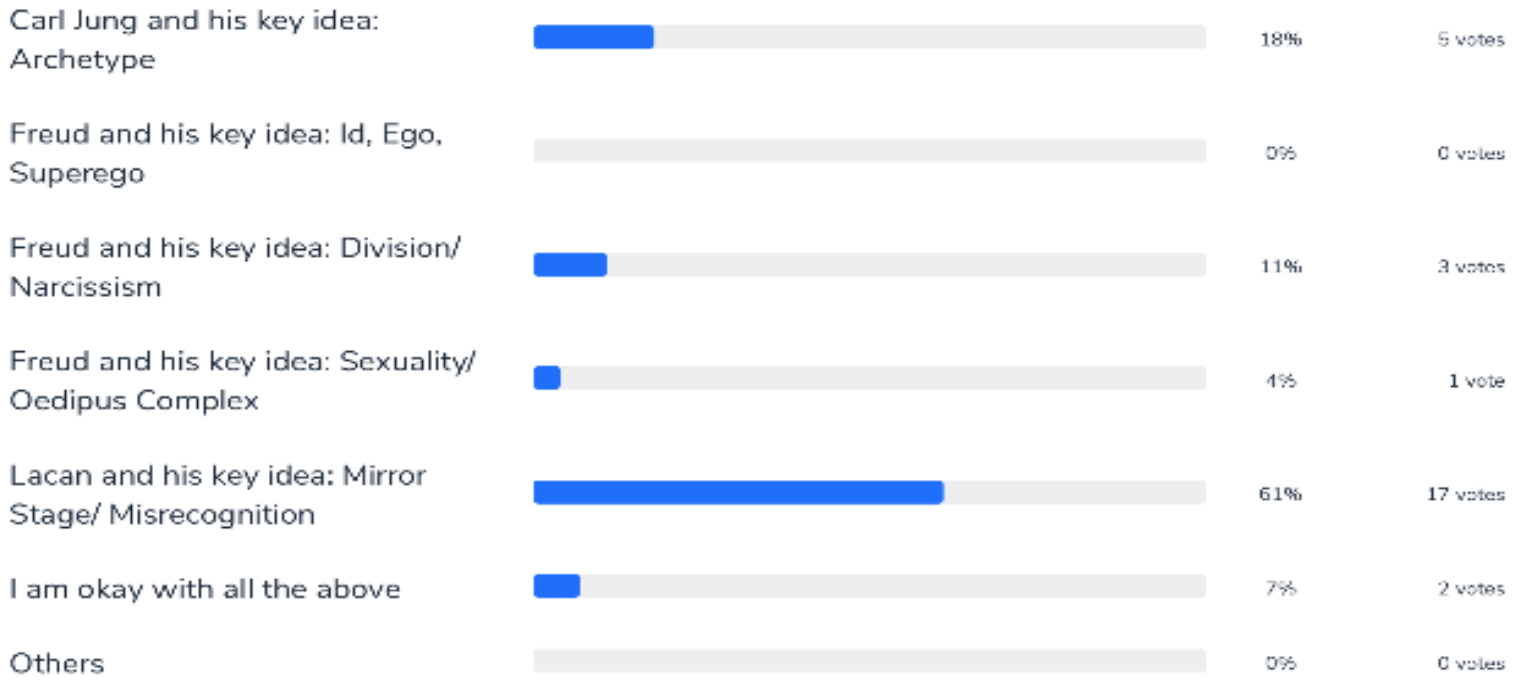

Figure 3: Students' responses to the subtopics that required the lecturer's attention to readdress during the live classes.

Creative Solutions in Teaching Creative Arts during COVID-19.

During the teaching and learning processes, the lecturer was also taking the steps in refining the theoretical and practical based courses. Visibly, theoretical based courses are more feasible to be conducted online as compared to practical based course. However, it is different in the case of music and film studies. Countering the social distancing guideline, it is indeed a great challenge in online learning in preparing, guiding and tutoring students for performance and production skills at the same time maintaining social distancing when they actually learn in the classroom or studio setting.

In the section above, the researchers had illuminated how they refined their theoretical classes which are commonly associated with their higher feasibility to be conducted online. However, concerns over practical based classes among academics' loom let alone running assessments for this type of class. Given that online learning was the only way lecturers were allowed to conducted classes, synchronous real time lectures and asynchronous learning through the activities created by the lecturers in the e-portal enabled the students to connect and socialise with their peers and continue their learning in a collaborative way. Hence, the teaching and learning case study presented in music and film studies presented a conundrum where it is a great challenge to conduct theoretical and practical based courses that involved aural skills, listening skills, auditory skills and hands-on skills which involve an affective and psychomotor learning domain. 
Not all the programmes and courses offered in the field of creative arts are adaptable to changing circumstances. Taking the example from both music and film programmes, without physical access to facilities such as musical instruments and filming equipment, can the science of teaching the arts be creatively re-conceptualised in order to learn to master a musical instrument or film equipment by observing, reading and listening to the instructor's online instruction? Both disciplines face the same challenge as the nature of the course structure involves practical skills and demonstration which requires students to participate in tutorial sessions in order to get a hands-on experience. In the music programme, it was a period of time music lecturers "struggle to make sense of new mandates" in redesigning the course plan for online, at the same period of time "drastically modify the way music is taught" (Stanley, 2020). Courses offered under the music programme could be divided into two different broad categories; theoretical skills (music theory, music history, musicianship, research) and practical skills (solo instrumental skills and ensemble playing).

One of the researchers is a music lecturer currently teaching music theory, music history and research methodology. For her, online teaching is an opportunity where a lecturer becomes a facilitator. The researcher had learnt to give the trust to her students, giving them adequate resources in various levels for them to explore further. Instead of giving a final exam in the form of a written test to test their knowledge and comprehension, she set an alternative assessment in the form of an ePortfolio. Such a change of the assessment method allowed a degree of flexibility in the assessment which was the key for students to explore different topics based on their interest, ability and capability.

The researcher had seen the possibility to teach theoretical based courses through online teaching and learning activities. Through individual learning reflection and response posted by the students weekly, lecturers could monitor their learning progress on a weekly basis to asses if the learning outcomes were achieved (Figure 4). For music practical skills, solo instrumental skills were evaluated based on individual music performance. But, for ensemble playing (duet, trio, chamber orchestra), choir and orchestra, it was a challenge to learn and evaluate the learning outcomes through online platforms. 
INTERNATIONAL JOURNAL OF ACADEMIC RESEARCH IN BUSINESS AND SOCIAL SCIENCES

Vol. 11, No. 14, Special Issue: Contemporary Business and Humanities Landscape Towards Sustainability, 2021, E-ISSN: 2222-6990 @ 2021 HRMARS

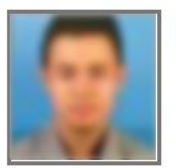

Re: Week 8 Music Theory Self Learning Reflection

by

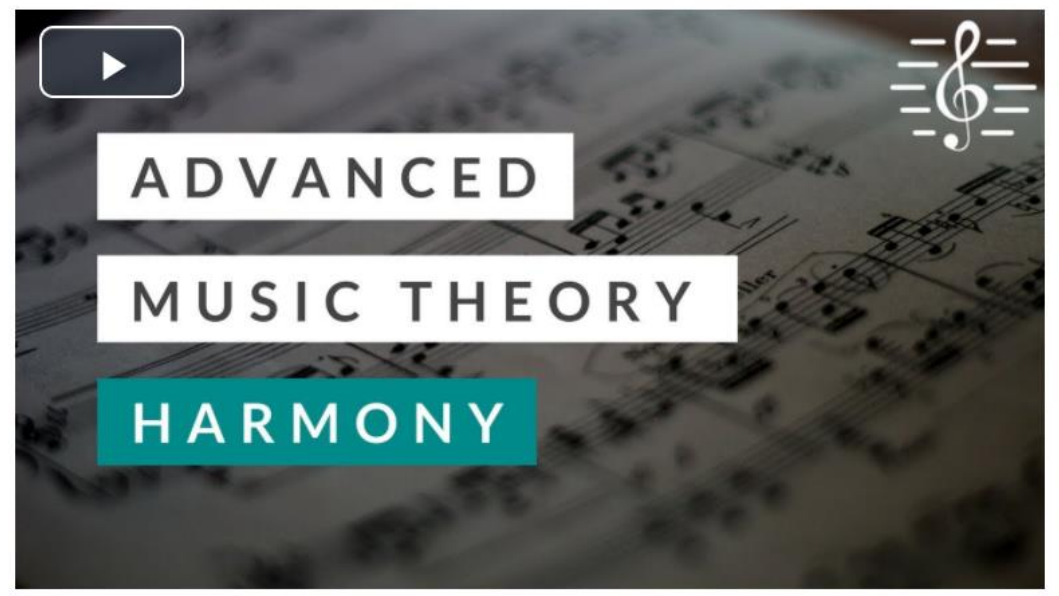

In my experience watching this video is that its like revising again from what madam Connie has teach us in class, and i found out the explanatory in this video very detailed and simple. For me, harmonizing the chord is very interesting and important that everything in this video with the knowledge from madam Connie can teach is more about how to do a harmony composition in our assignment. It is very interesting video and relax to watch too. 


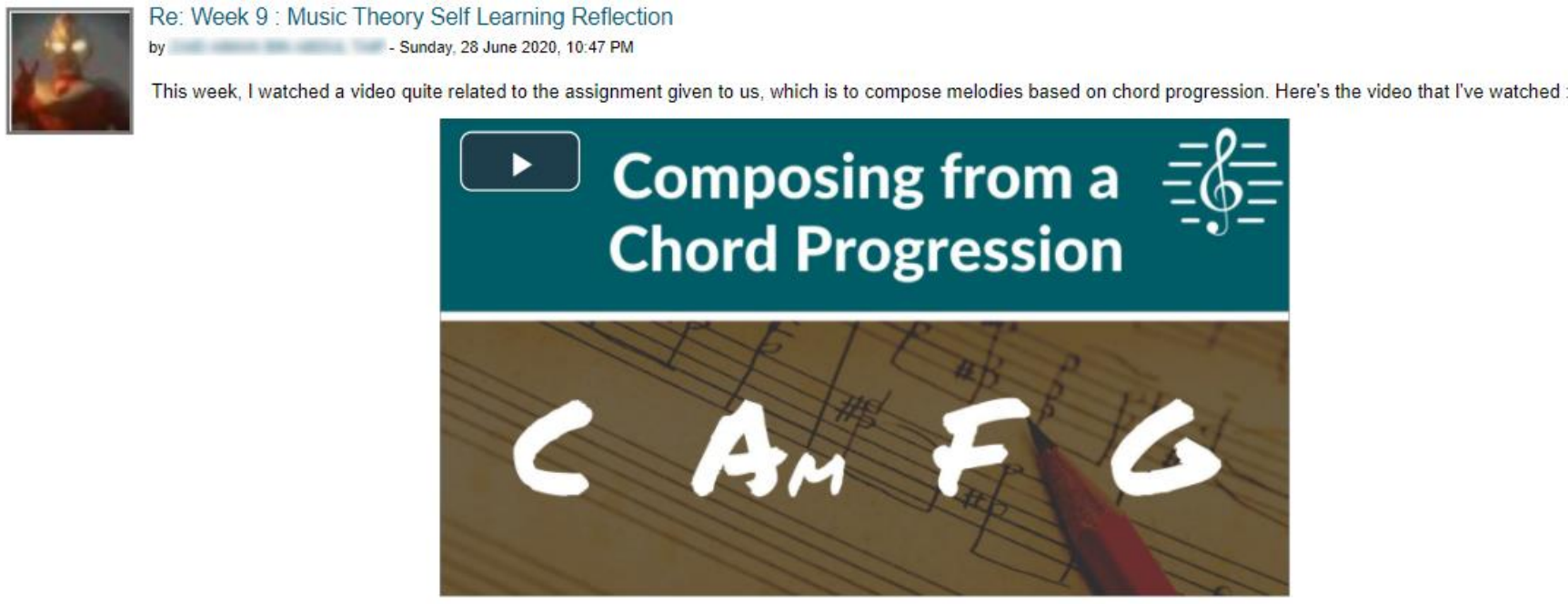

I found and learn a lot of things from this video especially on piano playing. To learn chords, I really think a piano/keyboard is needed to make things clearer. Main reason for me saying this is, in a chord scheme or progression, consisting of chords, which again consist of different notes starting from basically, the triads

\begin{abstract}
From what I understand, when a key is decided, we could come out with chord progression based on the key. And when a chord scheme is ready, we could still make it sounds more interesting by changing the chord formation or with inversion etc. In creating melodies based on the chord scheme, we have to know every notes which made up the chords. The notes is then given rhythm and change accordingly to the progression. The presenter showed various example with different styles ranging from ballad to rock and showed that it is made using the notes which create the chords in the progression itself. It is done by changing the speed, the meter (beats in a bar) and also the texture of the melody. The formation of chords could bring different feeling either by block chords, broken chords or alberti - affect the mood of the music.
\end{abstract}

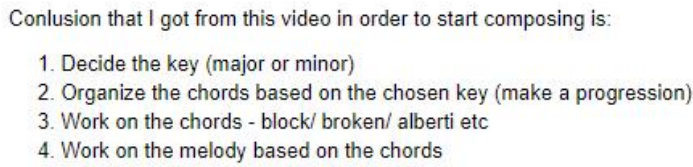

Permalink | Show parent | Edit | Split | Delete | Reply

Figure 4: Sample of two students' music theory self-learning reflection posted on UNIMAS eLEAP learning system.

Taking into consideration the students' current geographical locations and their feedback on their accessibility to the internet, it was a challenge to conduct a real-time practical skill assessment for instrumental courses which require collaborative skills in listening while performing together in an ensemble, choir and orchestra. Applicable to technical courses for film programme, recalibration of teaching and assessment methods were certainly needed. While rethinking the suitable alternative assessment for such courses and final project presentation which requires students to demonstrate both their theoretical understanding as well as their technical skills, the lecturers had taken the consideration of the current situation the students were facing by finding a more flexible approach in assessment based on the course learning outcome at the same time keeping up with student's progress from time to time and encouraging them to work with the available digital tools. In the new ecosystem of teaching and learning in the arts during the COVID-19 pandemic, it takes an amount of time in recalibrating the learning condition of arts. 

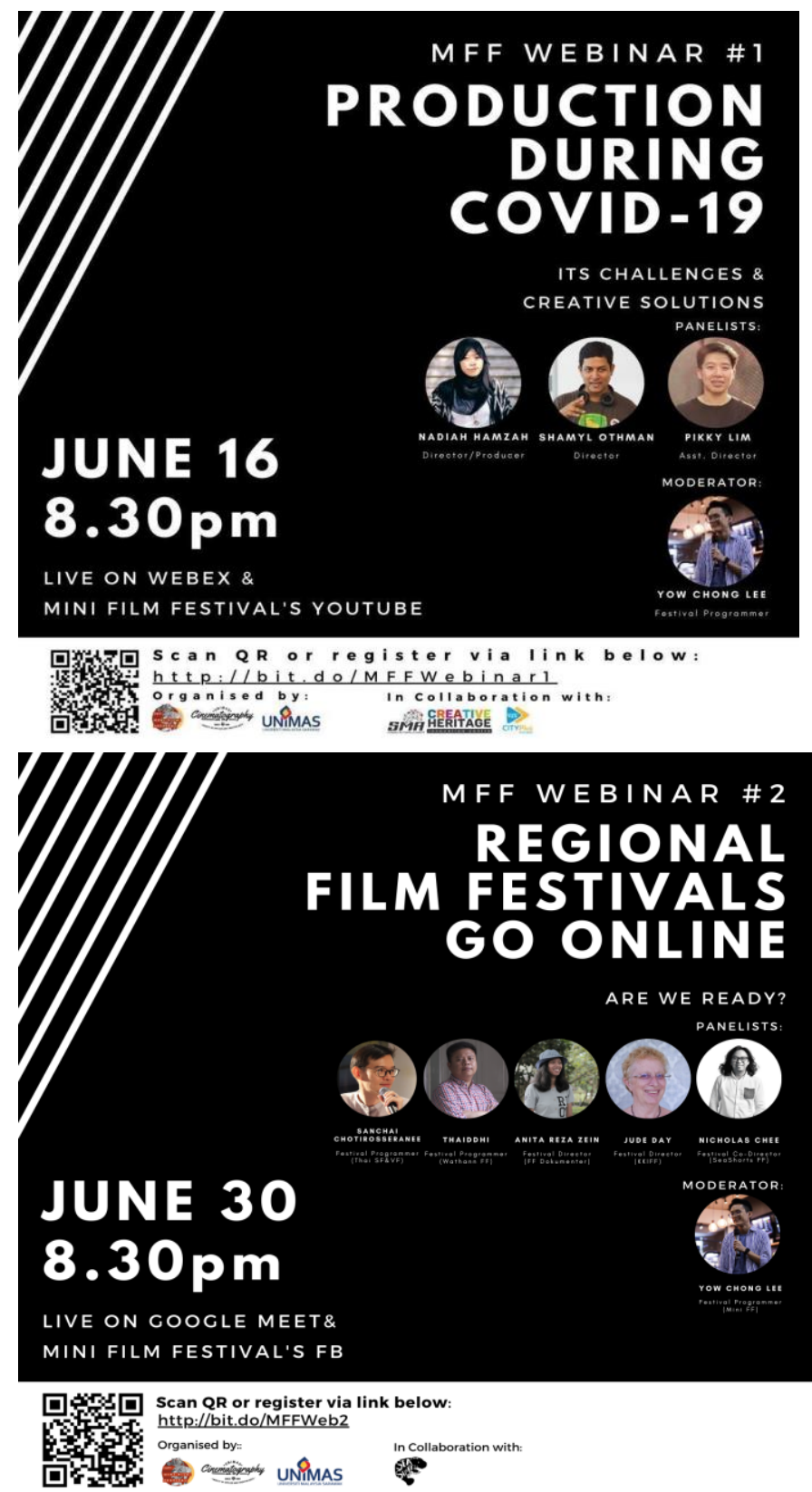

Figure 5: Posters of webinars which Yow coordinated and moderated

While COVID-19 has shaped and changed the administrative model of higher learning institutions worldwide, educators in the arts discipline have certainly recalibrated their roles not only in providing lectures or research publications online. They also showed the ability to bring the students closer to their community and industry to gain a certain degree of importance in fulfilling a holistic educational role in the post-pandemic condition. Addressing the fact that most film productions and musical performances were cancelled or postponed due to the pandemic, students' projects that often require them to conduct filming and live music performances to a wider audience were also affected. 
How could we provide such a linkage between students, community and the industry that inherently demands a great deal of networking as to pull them together in discussing issues, challenges and opportunities brought by COVID-19? For that reason, one of the researchers conducted two webinars by inviting filmmakers, film festival directors and programmers to shed light on the problems they encountered as well as creative solutions to deal with their conundrums while complying with production and live events' standard operating procedures (SOP)s. The webinars were opened to students and the general public for free and they could interact with these industry experts to gain insight on both challenges and creative solutions out of the predicament they faced (Figure 5). In such context, lecturers are expected to think and respond vigilantly in manoeuvring their industry and community network in order to provide learning opportunities to their students during the challenging time of COVID-19.

\section{Conclusion}

2020 was an historical year in human civilisation that delivered colossal lessons for academics to learn. It was a time when academics could have analysed the actual acoustics of an empty highway or felt a need to write multiple academic papers for the obligation of publication while working from home. It was also a time when they could have gone slow, seemingly, and earned a space for retrospectives to regain their physical, mental and spiritual wellbeing in a humanistic way. While many mourned the departure of families and friends because of the COVID-19 pandemic, there were also moments to celebrate the victory as the COVID-19 survivors. The COVID-19 phenomenon is bigger than just being a public health issue. Like all other sectors, academics live with the COVID-19 effect and have become a part of this global history of the biggest calamity on mankind since World War II.

Despite the many uneasy challenges in course planning, there are still opportunities of experimenting with the teaching and learning process to explore the delivery of the knowledge and skills in both theoretical and practical courses of music and film studies. The findings of this paper will hopefully provide a meaningful discourse about online learning where the challenges with a conventional sense of human touch were overcome with an attempt to provide a personalised learning experience in the teaching and learning process. As researchers of a higher education system, we acknowledge the need for an impact assessment of the COVID-19 pandemic. Within the scope of this article, there are still depths and unsettling queries that could be further explored. We hope this article will serve as a starting point for other researchers to offer and build a further academic discourse of what shapes creative arts in higher education and the industry into the future.

\section{References}

Academic Enhancement and Leadership Development Centre (n.d.). \#UMTeachOnline: Webinar series. University of Malaya. Retrieved June 29, 2020, https://adec.um.edu.my/online-training.

Abdul Rahim, A. F. (2020). Guidelines for online assessment in emergency remote teaching during the COVID-19 pandemic. Education in Medical Journal, 12(2), 59-68. https://doi.org/10.21315/eimj2020.12.2.6

Bunde-Birouste, A., Byrne, F., \& Kemp, L. (2019). Autoethnography. In Liamputtong P. (Ed.), Handbook of research methods in health social sciences (pp. 506-226). Springer Nature. 
INTERNATIONAL JOURNAL OF ACADEMIC RESEARCH IN BUSINESS AND SOCIAL SCIENCES

Vol. 11, No. 14, Special Issue: Contemporary Business and Humanities Landscape Towards Sustainability, 2021, E-ISSN: 2222-6990 @ 2021 HRMARS

Cambridge University Press (n.d.). 24/7 meaning in the Cambridge English Dictionary. Cambridge Dictionary. Retrieved June 29, 2020, https://dictionary.cambridge.org/dictionary/english/24-7

Carey, K. (2020). Everybody ready for the big migration to online college? Actually, no. The New York Times. https://www.nytimes.com/2020/03/13/upshot/coronavirus-online-college-classesunprepared.html

Centre for Academic Development. (2021). Webinar: online learning for all. Universiti Putra Malaysia. https://cade.upm.edu.my/online_learning_for_all/webinar-12393

Centre for Applied Learning and Multimedia (n.d.). Nurturing future graduates: CALM workshop [YouTube channel]. CALM UNIMAS. Retrieved February 6, 2021, https://www.youtube.com/channel/UC-z7142FHI2hi7VqwoJrCVw

Centre for Applied Learning and Multimedia. (2021). COVID-19 response: A quick guide for UNIMAS academics. Universiti Malaysia Sawarak. http://www.calm.unimas.my/covid19

Centre for Development of Academic Excellence. (2021). Online teaching \& learning - COVID-19: Resources. Universiti Sains Malaysia. https://cdae.usm.my/index.php/online-teachinglearning.

Centre for Disease Control and Prevention. (2020). Social distancing. U.S. Department of Health \& Human Services, Centre for Disease Control and Prevention. https://www.cdc.gov/coronavirus/2019-ncov/prevent-getting-sick/social-distancing.html

Chuah, K. M. (2020). Keeman's Edutech Channel [YouTube channel]. Retrieved June 29, 2020, https://www.youtube.com/channel/UCjRyNqfqz25LbhoK5QpVA3A

Cojocariu, V. M., Lazar, I., Nedeff, V., \& Lazar, G. (2014). SWOT analysis of e-learning educational services from the perspective of their beneficiaries. Procedia-Social and Behavioural Sciences, 116, 1999-2003.

Corbera, E., Anguelovski, I., Honey-Rosés, J., \& Ruiz-Mallén, I. (2020). Academia in the time of COVID19: Towards an ethics of care. Planning Theory \& Practice, 21(2), 191-199. https://doi.org/10.1080/14649357.2020.1757891

Dhawan, S. (2020). Online Learning: A Panacea in the time of COVID-19 crisis. Journal of Educational Technology Systems, 49(1), 5-22.

https://journals.sagepub.com/doi/pdf/10.1177/0047239520934018

Dotterweich, D. P., \& Rochelle, C. F. (2012). Online, instructional television and traditional delivery: Student characteristics and success factors in business statistics. American Journal of Business Education, 5(2), 129-138.

Erikson, D. (2020). Q\&A: A founder of distance education weighs in on its educational benefits. University of Wisconsin-Madison. https://news.wisc.edu/qa-a-founder-of-distance-educationweighs-in-on-its-educational-benefits/

Flaherty, C. (2020). Zoom Boom. Inside Higher Ed. https://www.insidehighered.com/news/ 2020/04/29/synchronous-instruction-hot-right-now-it-sustainable

Allo, G. M. D. (2020). Is the online learning good in the midst of Covid-19 pandemic? The case of EFL learners. Jurnal Sinestesia, 10(1): 1-10. https://sinestesia.pustaka.my.id/journal/article/view/24/1

Huang, R., Tlili, A., Chang, T. W., Zhang, X., Nascimbeni, F., \& Burgos, D. (2020a). Disrupted classes, undisrupted learning during COVID-19 outbreak in China: Application of open educational practices and resources. Smart Learning Environments, 7(19). https://doi.org/10.1186/s40561020-00125-8 
INTERNATIONAL JOURNAL OF ACADEMIC RESEARCH IN BUSINESS AND SOCIAL SCIENCES

Vol. 11, No. 14, Special Issue: Contemporary Business and Humanities Landscape Towards Sustainability, 2021, E-ISSN: 2222-6990 @ 2021 HRMARS

Huang, R., Liu, D., Tlili, A., Yang, J., \& Wang, H. (2020b). Handbook on facilitating flexible learning during educational disruption: The Chinese experience in maintaining undisrupted learning in COVID-19 outbreak. Smart Learning Institute of Beijing Normal University.

Johns Hopkins University \& Medicine (n.d.). COVID-19 dashboard by the Centre for Systems Science and Engineering at Johns Hopkins University \& Medicine. Coronavirus Resource Centre, Johns Hopkins University \& Medicine. Retrieved August 18, 2020,

https://coronavirus.jhu.edu/map.html

Kalbana Perimbanayagam. (2020). Ministry urges universities to resume 2nd semester between April 27 and June 1. New Straits Times. https://www.nst.com.my/news/nation/2020/03/579004/ ministry-urges-universities-resume\%C2\%A02nd-semester-between-april\%C2\%A027-and-june

Khalili, H. (2020). Online interprofessional education during and post the COVID-19 pandemic: A commentary. Journal of Interprofessional Care, 34(5), 687-690.

https://doi.org/10.1080/13561820.2020.1792424

Landau, E. (2020). University lectures to go online until Dec 31, except for 5 groups. New Straits Times. https://www.nst.com.my/news/nation/2020/05/595758/university-lectures-go-online-untildec-31-except-5-groups

Lashuel, H. A. (2020). The busy lives of academics have hidden costs-and universities must take better care of their faculty members. Nature. https://www.nature.com/articles/d41586-02000661-w

LeBlanc, P. (2020). COVID-19 has thrust universities into online learning-how should they adapt? Brookings. https://www.brookings.edu/blog/education-plus-development/2020/03/30/covid19-has-thrust-universities-into-online-learning\%E2\%81\%A0-how-should-they-adapt/

Lederman, D. (2020), Will shift to remote teaching be boon or bane for online learning? Inside Higher Ed. https://www.insidehighered.com/digital-learning/article/2020/03/18/most-teachinggoing-remote-will-help-or-hurt-online-learning

Lee, S. (2020). Sabah student stays overnight in tree to get better Internet connection for online university exams. The Star. https://www.thestar.com.my/news/nation/2020/06/16/sabah-unistudent-stays-overnight-in-tree-to-get-better-internet-connection-for-online-exams

Li, X., Yang, Y., Chu, S. K. W., Zainuddin, Z., \& Zhang, Y. (2020). Applying blended synchronous teaching and learning for flexible learning in higher education: An action research study at a university in Hong Kong, Asia Pacific Journal of Education, 1-17.

https://doi.org/10.1080/02188791.2020.1766417

Ling, D. S. (2020). This pandemic is not an extended sabbatical. Nature. https://www.nature.com/articles/d41586-020-01591-3

McBrien, J. L., Cheng, R., \& Jones, P. (2009). Virtual spaces: Employing a synchronous online classroom to facilitate student engagement in online learning. The International Review of Research in Open and Distributed Learning, 10(3), 1-17. https://files.eric.ed.gov/fulltext/EJ847763.pdf

Ministry of Higher Education. (2020), Pengendalian Aktiviti Akademik Di Kampus Institusi Pendidikan Tinggi Semasa dan Pasca Perintah Kawalan Pergerakan. Ministry of Higher Education, Malaysia. http://www.mohe.gov.my/en/media-mohe/press-statement/1126-pengendalianaktiviti-akademik-di-kampus-institusi-pendidikan-tinggi-semasa-dan-pasca-perintah-kawalanpergerakan 
INTERNATIONAL JOURNAL OF ACADEMIC RESEARCH IN BUSINESS AND SOCIAL SCIENCES

Vol. 11, No. 14, Special Issue: Contemporary Business and Humanities Landscape Towards Sustainability, 2021, E-ISSN: 2222-6990 @ 2021 HRMARS

Miwil, O. (2020). UMS offers scholarship to 'tree girl' Veveonah. New Straits Times. https://www.nst.com.my/news/nation/2020/06/603160/ums-offers-scholarship-tree-girlveveonah

MPPUPM [@MPPUPMofficial]. (2020). Platform Kelas Online Yang Disarankan Pelajar. Korang sarankan pensyarah pakai apa? Admin suka pakai Google Meet. [Image attached] [Tweet]. Twitter. https://twitter.com/MPPUPMofficial/status/1268118944742694914

Nechvatal, J. (2011). Immersion into noise. Open Humanities Press.

O'Callaghan, Craig (2020). QS World University Rankings by Subject 2020: Methodology. QS Top Universities. https://www.topuniversities.com/subject-rankings/methodology

Pfordten, D. (2020). Interactive: With no physical classes until Dec 31, local varsities are switching exam methods. The Star. https://www.thestar.com.my/news/nation/2020/06/17/interactivewith-no-physical-classes-until-dec-31-local-varsities-are-switching-exam-methods

Phirangee, K., \& Malec, A. (2017). Othering in online learning: An examination of social presence, identity, and sense of community. Distance Education, 38(2), 160-172.

https://doi.org/10.1080/01587919.2017.1322457

Reissman, C. K. (2005). Narrative analysis. In N. Kelly, C. Horrocks, K. Milnes, B. Roberts, \& D. Robertson (Eds.), Narrative, memory and everyday life (pp. 1-8). University of Huddersfield Press.

Sani, R. (2020). Making the switch to online learning. New Straits Times. https://www.nst.com.my/education/2020/03/578431/making-switch-online-learning

Singh, V., \& Thurman, A. (2019). How many ways can we define online learning? A systematic literature review of definitions of online learning (1988-2018). American Journal of Distance Education, 33(4), 289-306.

Stanley, A. M. (2020). AEPR special focus issue: an international view of policy and music teacher professional development. Arts Education Policy Review, 122(1), 1-3.

https://doi.org/10.1080/10632913.2020.1756019

Sukumaran, T. (2020). Coronavirus: Malaysia in partial lockdown from March 18 to limit outbreak. South China Morning Post. https://www.scmp.com/week-asia/healthenvironment/article/3075456/coronavirus-malaysias-prime-minister-muhyiddin-yassin

Teoh, P. Y. (2020). Covid-19: Universities activate e-learning mode. New Straits Times. https://www.nst.com.my/news/nation/2020/03/574766/covid-19-universities-activate-elearning-mode

THE World University Rankings (2020). THE World University Rankings 2020: Methodology. Times Higher Education. https://www.timeshighereducation.com/world-university-rankings/worlduniversity-rankings-2020-methodology

UNIMAS News (2020). Preventive Actions against COVID-19: Frequently asked questions for students. Universiti Malaysia Sarawak. http://www.news.unimas.my/eventdetail/6891/-/preventiveactions-against-covid-19-frequently-asked-questions-for-students

United Nations Educational, Scientific, and Cultural Organisation (n.d.). Education: From disruption to recovery. Retrieved August 11, 2020, https://en.unesco.org/covid19/educationresponse

Williamson, B., Eynon, R., \& Potter, J. (2020). Pandemic politics, pedagogies and practices: Digital technologies and distance education during the coronavirus emergency. Learning, Media and Technology, 45(2), 107-144. https://doi.org/10.1080/17439884.2020.1761641 
Vol. 11, No. 14, Special Issue: Contemporary Business and Humanities Landscape Towards Sustainability, 2021, E-ISSN: 2222-6990 @ 2021 HRMARS

World Health Organisation (n.d.). COVID-19: Physical distancing. Retrieved August 11, 2020, https://www.who.int/westernpacific/emergencies/covid-19/information/physical-distancing 